\title{
Investigation of Bioequivalence Between Brand-name and Generic Irinotecan Products
}

\author{
KEN-ICHI SAITO ${ }^{1,2}$, YUTAKA INOUE ${ }^{2}$, YOJI IKEGAMI ${ }^{2}$, IZUMI NANBO ${ }^{2}$, MARI ONOZUKA $^{2}$, \\ KAZUMI SANO ${ }^{2}$, HISAHIRO YOSHIDA ${ }^{2}$, TOSHIHIRO SAKAMOTO ${ }^{3}$, EMI TATEBAYASHI ${ }^{3}$, \\ KEN-ICHI FUJITA ${ }^{4}$, YASUTSUNA SASAKI ${ }^{5}$ and TAKAKI KITAZAWA ${ }^{3,6}$ \\ ${ }^{1}$ Department of Pharmacy Services, Saitama Medical Center, Saitama Medical University, Saitama, Japan; \\ ${ }^{2}$ Department of Drug Metabolism and Disposition, Meiji Pharmaceutical University, Kiyose, Japan; \\ ${ }^{3}$ Department of Pharmacy Services, Saitama Medical University International Medical Center, Saitama, Japan; \\ ${ }^{4}$ Institute of Molecular Oncology, Showa University, Tokyo, Japan; \\ ${ }^{5}$ Division of Medical Oncology, Department of Medicine, \\ Showa University School of Medicine, Tokyo, Japan; \\ ${ }^{6}$ Department of Pharmacy Services, Saitama Medical University, Moroyama, Japan
}

\begin{abstract}
Background/Aim: To investigate bioequivalence among generic and brand-name irinotecan products. Materials and Methods: Products of Yakult and Daiichi-Sankyo (brandname products), Sandoz, Nippon Kayaku, Taiho, and Sawai were compared with respect to their composition and antitumor activity. Results: High-performance liquid chromatography demonstrated that related substances were within the acceptable range. The 3-(4,5-dimethylthiazol-2-yl)-2,5-diphenyltetrazolium bromide assay revealed significant differences in cytotoxicity for four cancer cell lines among the products. The concentration of the active compound SN-38 was highest in Yakult's product (23.82 $\mathrm{ng} / \mathrm{ml})$ and lowest in Daiichi-Sankyo's product (8.96 $\mathrm{ng} / \mathrm{ml}$ ). MTT assay data were correlated with the $S N-38$ concentration, suggesting that it influenced differences in cytocidal activity among products. However, the $S N-38$ concentration was far lower than that of irinotecan $(20 \mathrm{mg} / \mathrm{ml})$, suggesting a negligible clinical effect. Metabolism of irinotecan to $\mathrm{SN}-38$ or open-ring forms did not differ significantly among the products. Conclusion: The generic products showed equivalent efficacy and safety to the brand-name products.
\end{abstract}

Generic products are expected to show equivalence to brandname products with respect to the dosage form, safety, efficacy and quality, while reducing medical expenses due to

Correspondence to: Yoji Ikegami, Department of Drug Metabolism and Disposition, Meiji Pharmaceutical University, 2-522-1 Noshio, Kiyose-shi, Tokyo 204-8588, Japan. Tel: +81 424958470, e-mail: yoji@my-pharm.ac.jp

Key Words: Cytotoxicity, chemotherapy, generic, irinotecan, bioequivalence. their lower cost. For oral drugs, equivalence between generic and brand-name products must be demonstrated by dissolution and bioequivalence tests. On the other hand, while quality assurance tests, such as purity tests, are required for injectable products, bioequivalence tests are not compulsory. Therefore, only certain companies voluntarily perform bioequivalence tests of injectable products. For anticancer agents, excluding some hormonal agents, bioequivalence studies in healthy volunteers are prohibited. However, some reports have been published comparing safety and pharmacokinetics between brand-name and generic injectable products. For example, the safety and pharmacokinetics of paclitaxel were reported to be similar between brand-name and generic products in patients with cancer (1-4). In contrast, it has been reported that generic forms of docetaxel, another taxane anticancer agent, cause more serious febrile neutropenia than the brand-name product (5). Moreover, cisplatin generics were found to cause more severe nephropathy and hematological toxicity than the brand-name product (6-8).

Irinotecan is a DNA topoisomerase I inhibitor derived from camptothecin that shows broad-spectrum strong antitumor activity (9). It is a prodrug, and carboxylesterases in the liver and other tissues convert it to the active metabolite, 7-ethyl10-hydroxy-camptothecin (SN-38) (10), which has 1000-fold stronger pharmacological activity than the parent compound (11). Irinotecan is a key drug for treating various cancer types, including colorectal (12), lung (13), gastric cancer (14), breast (15), cervical (16), and ovarian (17). Generic products for irinotecan were released in Japan in May 2009.

Irinotecan is a semisynthetic derivative of camptothecin extracted from Camptotheca acuminata or Nothapodytes foetida, which are native to China $(18,19)$. It has been 
Table I. List of irinotecan products and manufacturers.

\begin{tabular}{lcc}
\hline Type of product & Name & Manufacturer \\
\hline Brand name & Campto for $i . v$. infusion & Yakult Honsha \\
Generic & Irinotecan Hydrochloride Intravenous Infusion [SANDOZ] & Sandoz \\
Generic & Irinotecan for $i . v$. infusion [NK] & Nippon Kayaku Co., Ltd \\
Generic & Irinotecan Hydrochloride $i . v$. infusion「TAIHO」 & Taiho Pharmaceutical Co., Ltd. \\
Generic & Irinotecan Hydrochloride & Sawai Pharmaceutical Co., Ltd. \\
Brand name & Topotecin Intravenous Drip Infusion & Daiichi-Sankyo Co., Ltd. \\
\hline
\end{tabular}

reported that the plant used as a source material differs among pharmaceutical companies and that levels of contaminants vary as a consequence (20). Antitumor activity is also influenced by $\mathrm{pH}$-related lactone ring opening, since the lactone form shows higher antitumor activity than the carboxylate form. These features of irinotecan suggest the potential for safety and pharmacokinetics to differ between the brand-name and generic products, but there have been no reports about this issue.

Accordingly, the present study was performed to investigate in vitro bioequivalence among the irinotecan products of various pharmaceutical companies by performing various tests, including assessment of purity, cytocidal activity, $\mathrm{pH}$-dependent lactone ring opening, cytotoxicity of Y3 (a related substance), and formation of active metabolites by human hepatic microsomes. Our findings suggest that the brand-name and generic products would be expected to have equivalent efficacy and safety.

\section{Materials and Methods}

Anticancer agents. The reference formulation (brand-name product) was Campto ${ }^{\circledR}$ (Yakult Honsha,Tokyo, Japan), while the other products studied were Topotecin ${ }^{\circledR}$ (brand-name product) and four generic products (Table I). Authentic specimens of the following potential contaminants were supplied by Yakult Honsha: 3,10diethyl-8-[(4-piperidinopiperidino)carbonyloxy]furo $\left[3^{\prime}, 4^{\prime}: 6,7\right]$ indolizino-[1,2-b]quinoline-1,13(3H,11H)-dione (D1); 10-ethyl-2methyl-3-propionyl-8-[(4-piperidinopiperidino)carbonyloxy] indolizino[1,2-b]-quinoline-1(11H)-one (D3); (4S)-4,11-diethyl4,12-dihydroxy-9-[(4-piperidinopiperidino)carbonyloxy- $1 \mathrm{H}$ pyrano[3', 4':6,7]-indolizino[1,2-b]quinoline-3,14(4H,12H)-dione (Y1); (4S)-4,11-diethyl-4,9,12-trihydroxy-1H-pyrano[3',4':6,7] indolizino[1,2-b]quinoline-3,14(4H,12H)-dione (Y3), and 4-ethyl2-[6-(4-ethyl-4-hydroxy-3,8(1H,7H)-dioxopyrano[3,4-c]pyridyl)]-6(piperidinopiperidino)-carbonyloxyquinoline-3-carboxylic acid (U1) (Figure 1).

Cell lines and culture. A small cell lung cancer cell line (PC-6) was obtained from the Second Department of Internal Medicine of Nagasaki University (Nagasaki, Japan), a non-small cell lung cancer cell line (PC-9) was from Kinki University (Higasiosaka-shi, Japan), and another non-small cell lung cancer cell line (A549) and an ovarian cancer cell line (NIH:OVCAR-3) were from the Riken Cell Bank, Tsukuba, Ibaraki, Japan.

A549 cells were incubated in Dulbecco's modified Eagle's medium (DMEM) (Wako, Osaka, Japan), while PC-6, PC-9, and NIH:OVCAR-3 cells were incubated in RPMI-1640 medium (Sigma-Aldrich, Tokyo, Japan). Both media contained $10 \%$ fetal bovine serum and incubation was at $37^{\circ} \mathrm{C}$ under $5 \% \mathrm{CO}_{2}$.

Assessment of purity. High-performance liquid chromatography (HPLC) was performed using a Hitachi Detector L-2400 and a Hitachi Pump L-2130 (Hitachi, Tokyo, Japan). The detection wavelength was $254 \mathrm{~nm}$. The analytical column was a Capcell Pak C18 MG (5 $\mu, 3.0 \Phi \times 150 \mathrm{~mm}$ ) from Shiseido (Tokyo, Japan). Mobile phase A was a mixture of $50 \mathrm{mM}$ formic acid buffer $(\mathrm{pH}$ 5.1), acetonitrile and $\mathrm{MeOH}$ at 75:10:15 (v/v/v), while mobile phase $\mathrm{B}$ was a mixture of $50 \mathrm{mM}$ formic acid buffer ( $\mathrm{pH} 5.1$ ), acetonitrile and $\mathrm{MeOH}$ at 55:30:15 (v/v/v). Elution was performed at a flow rate of $1.0 \mathrm{ml} / \mathrm{min}$ and a temperature of $50^{\circ} \mathrm{C}$ using the following protocol: gradient elution from $\mathrm{A}$ to $\mathrm{B}(30 \mathrm{~min}) \rightarrow \mathrm{A}(1 \mathrm{~min}) \rightarrow$ equilibration (5 $\mathrm{min})$.

Cytotoxicity test. Small cell lung cancer cells (PC-6), non-small cell lung cancer cells (PC-9, A549) and ovarian cancer cells (NIH:OVCAR-3) were used to evaluate cytotoxicity by the 3-(4,5dimethylthiazol-2-yl)-2,5-diphenyltetrazolium bromide (MTT) assay. Cells in the logarithmic growth phase were suspended in $0.05 \%$ trypsin-EDTA (Nacalai Tesque, Kyoto, Japan) and adjusted to $5.6 \times 10^{3}$ cells $/ \mathrm{ml}$ in irinotecan-free medium. This suspension was inoculated at a volume of $1,800 \mu \mathrm{l} /$ well $(1,000$ cells/well $)$ into a $96-$ well microplate, and serial dilutions of each product in medium were added to the wells. After $72 \mathrm{~h}$ of incubation, $5 \mathrm{mg} / \mathrm{ml}$ MTT (Nacalai Tesque) was added at $20 \mu \mathrm{l} /$ well and incubation was continued for 4 h. Then centrifugation $\left(400 \times g\right.$ at $\left.4^{\circ} \mathrm{C}\right)$ was performed for $10 \mathrm{~min}$. After the medium was discarded, dimethyl sulfoxide was added at a volume of $200 \mu \mathrm{g} / \mathrm{well}$, and the absorbance was measured at $570 \mathrm{~nm}$ using a microplate reader (reference wavelength of $650 \mathrm{~nm}$ ).

Formation of open-ring irinotecan. Irinotecan adopts closed- and open-ring forms under acidic and basic conditions, respectively (21). Because opening the lactone ring alters the antitumor activity of irinotecan, the extent of formation of its open-ring form was compared among the products. During incubation of each product in human plasma $(\mathrm{pH} 7.4 \pm 0.05)$ at $37^{\circ} \mathrm{C}$, samples were collected over time and deproteinized for analysis by HPLC (fluorescence detector: excitation at $380 \mathrm{~nm}$ and emission at $550 \mathrm{~nm}$ ). The concentration of the closed-ring form relative to the total irinotecan 


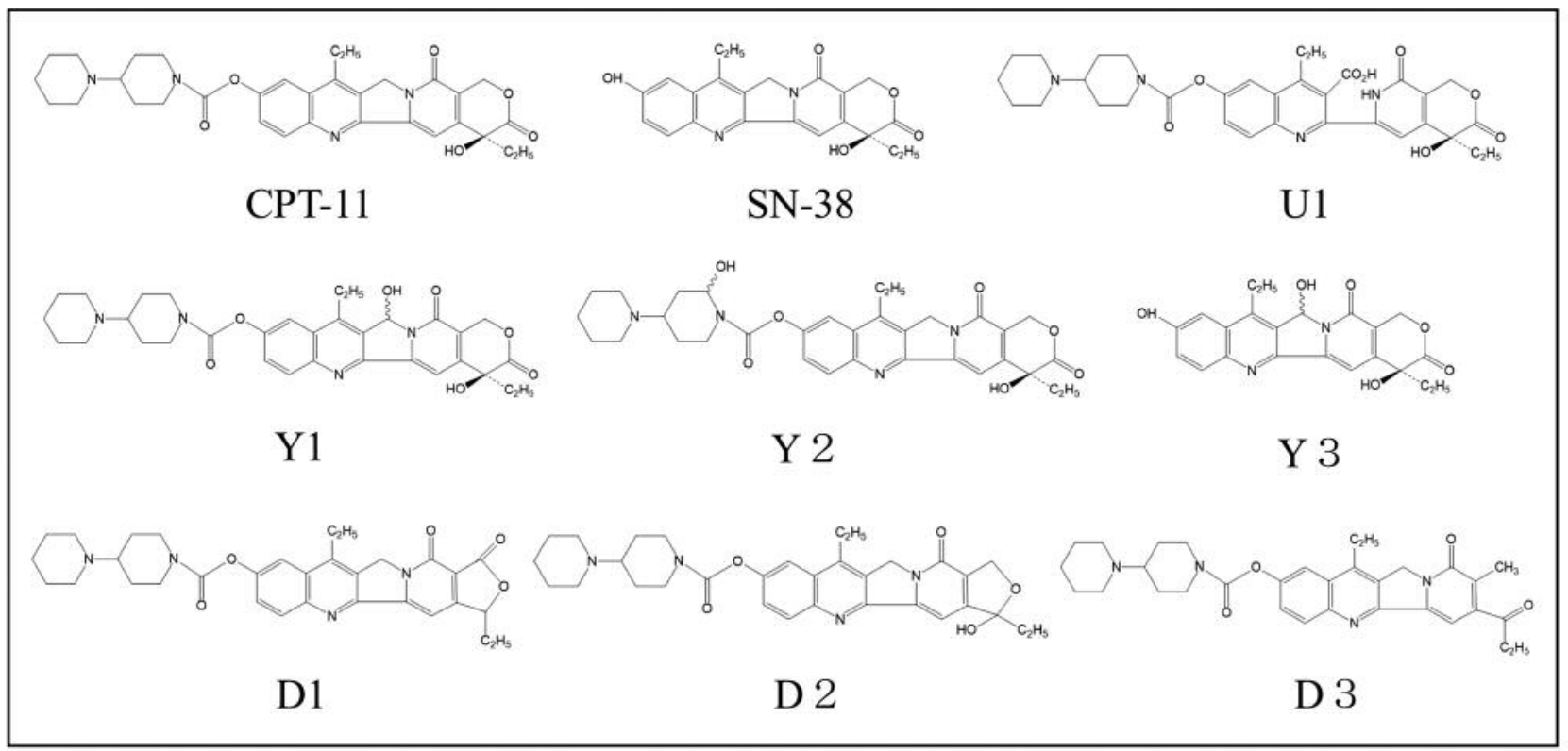

Figure 1. Structure of irinotecan and related substances.

concentration was determined over time, with the concentration of the closed-ring form at the start of incubation being set at $100 \%$.

$S N-38$ formation by human hepatic microsomes. An aliquot $(30 \mu \mathrm{l})$ of $25 \mathrm{mg} / \mathrm{ml}$ human hepatic microsomes (Biopredic, Saint-Grégoire, France) was solubilized by adding $6 \mu \mathrm{l}$ of $1 \%$ Triton $\mathrm{X}-100$. The solubilized microsomes were added to $60 \mu \mathrm{l}$ of $\mathrm{NaH}_{2} \mathrm{PO}_{4}(0.1 \mathrm{~mol} / \mathrm{l}$ $\mathrm{pH}$ 7.4) together with $51 \mu \mathrm{l}$ of water and $3 \mu \mathrm{l}$ of irinotecan $(0.8 \mathrm{mg} / \mathrm{ml})$ for incubation at $37^{\circ} \mathrm{C}$. Samples were collected after 2, 4, and $6 \mathrm{~min}$ and were immediately added to acetonitrile on ice $\left(0^{\circ} \mathrm{C}\right)$ for deproteinization. After centrifugation for $5 \mathrm{~min}$ at $21,000 \times \mathrm{g}$ and $4^{\circ} \mathrm{C}$, $10 \mu \mathrm{l}$ of the supernatant was injected into the HPLC system by an autosampler for analysis (fluorescence detector: excitation at $380 \mathrm{~nm}$ and emission at $550 \mathrm{~nm}$ ).

Cytotoxicity of $Y 3$ and $S N-38$. Because the potential contaminant $\mathrm{Y} 3$ has a similar structure to $\mathrm{SN}-38$, even a low content of $\mathrm{Y} 3$ can influence a product's cytocidal activity. Therefore, the cytotoxicity of Y3 for small-cell lung cancer cell line PC-6 and non-small cell lung cancer cell line PC-9 was evaluated by the MTT assay and the Y3 content of each product was measured by HPLC.

\section{Results}

Comparison of impurities among the products. When impurities were measured by HPLC and compared among the products, peaks of related substances with known structures (such as D1, D3, Y1, and U1) were detected in addition to the peaks of irinotecan and SN-38 (Table II). While the peak area of each related substance varied among the products, it was always less than $0.2 \%$, which is the threshold specified by "Impurities in New Drug Products" in the International Conference on Harmonisation (ICH) guidelines (22). Peaks of unknown contaminants were also noted, but the peak area of each contaminant was less than $0.1 \%$. These results suggest that the products were equivalent with respect to their impurities.

Cytotoxicity. When in vitro cytocidal activity was compared between the products by the MTT assay (Table III), the $50 \%$ inhibitory concentration $\left(\mathrm{IC}_{50}\right)$ for PC-6 showed a significant difference between the reference formulation and three other products.In addition, the $\mathrm{IC}_{50}$ values for $\mathrm{PC} 9$ and NIH:OVCAR-3 cells were significantly different between the reference formulation and four or five other products, respectively. When the $\mathrm{SN}-38$ content was measured in the impurity test, it was significantly lower in the products of Sandoz, Sawai, and Daiichi-Sankyo than in the reference formulation (Table IV). The difference of $\mathrm{IC}_{50}$ against PC-6 cells among the products was significantly related to the $\mathrm{SN}-38$ content $\left(\mathrm{r}^{2}=0.813, p<0.05\right)$ as it was against PC-9 cells $\left(\mathrm{r}^{2}=0.951, p<0.01\right)$, but not A549 cells $\left(\mathrm{r}^{2}=0.326, p>0.05\right)$ nor NIH:OVCA R-3 cells $\left(\mathrm{r}^{2}=0.123, p>0.05\right)$. Yakult's product had the highest $\mathrm{SN}-38$ content $(23.82 \pm 3.55 \mathrm{ng} / \mathrm{ml})$ and the strongest cytotoxicity, while the product of Daiichi-Sankyo had the lowest $\mathrm{SN}-38$ content $(8.96 \pm 0.62 \mathrm{ng} / \mathrm{ml})$ and tended to exhibit weaker cytotoxicity than the other products against all cell lines.

Open-ring form. When each product was incubated in human plasma, the decrease in the lactone (closed-ring) form of irinotecan over time did not significantly differ among the 
Table II. Peak area ratios of irinotecan and contaminants. High-performance liquid chromatography peak area (\%) profiles of the reference formulation and other products are shown. The peak area ratio of each contaminant was $<0.2 \%$ and was acceptable by International Conference on Harmonisation guidelines.

\begin{tabular}{lcccccc}
\hline & \multicolumn{5}{c}{ Product manufacturer } \\
\cline { 2 - 7 } Compound & Yakult & Sandoz & Nippon Kayaku & Taiho & Sawai & Daiichi-Sankyo \\
\hline Irinotecan (closed) & 99.56 & 99.52 & 99.60 & 99.46 & 99.52 & 99.47 \\
Irinotecan (open) & 0.14 & 0.18 & 0.20 & 0.22 & 0.11 & 0.01 \\
D1 & 0.05 & 0.01 & 0.02 & 0.11 & 0.09 & 0.01 \\
D3 & 0.10 & 0.08 & 0.06 & 0.06 & 0.08 & 0.11 \\
Y1 & 0.04 & 0.06 & 0.01 & 0.01 & 0.01 & 0.06 \\
U1 & 0.06 & 0.02 & 0.06 & 0.04 & 0.05 & 0.04 \\
Unknown 1 & n.d. & n.d. & 0.01 & 0.07 & 0.08 & 0.01 \\
Unknown 2 & n.d. & 0.06 & 0.01 & 100.00 & 100.00 & 0.09 \\
Other & 0.05 & 0.07 & 100.00 & & 100.00 \\
Total & 100.00 & 100.00 & &
\end{tabular}

Table III. Cytotoxicity of each product. The 50\% inhibitory concentration $\left(I_{50}\right)$ of each product was determined by the 3-(4,5-dimethylthiazol-2yl)-2,5-diphenyltetrazolium bromide assay. The cytotoxicity of the other products was weaker than that of the Yakult reference formulation.

\begin{tabular}{|c|c|c|c|c|c|c|}
\hline \multirow[b]{3}{*}{ Cell line } & \multicolumn{6}{|c|}{$\mathrm{IC}_{50}(\mu \mathrm{M})$} \\
\hline & \multicolumn{6}{|c|}{ Product manufacturer } \\
\hline & Yakult & Sandoz & Nippon Kayaku & Taiho & Sawai & Daiichi-Sankyo \\
\hline PC-6 & $1.37 \pm 0.05$ & $1.86 \pm 0.06^{* *}$ & $1.38 \pm 0.08$ & $1.59 \pm 0.09 * *$ & $1.39 \pm 0.05$ & $2.03 \pm 0.07 * *$ \\
\hline PC-9 & $7.46 \pm 0.68$ & $12.36 \pm 0.47 * *$ & $8.01 \pm 0.51$ & $9.07 \pm 0.48 * *$ & $9.14 \pm 0.29^{* *}$ & $16.70 \pm 0.56^{* *}$ \\
\hline A549 & $44.99 \pm 6.90$ & $77.09 \pm 8.89 * *$ & $64.07 \pm 10.21 * *$ & $75.17 \pm 7.95 * *$ & $61.61 \pm 7.63 * *$ & $72.32 \pm 6.89 * *$ \\
\hline NIH:OVCAR-3 & $16.66 \pm 0.71$ & $20.85 \pm 1.37 * *$ & $23.08 \pm 3.44 * *$ & $24.70 \pm 2.26^{* *}$ & $24.63 \pm 0.95^{* *}$ & $24.08 \pm 2.13 * *$ \\
\hline
\end{tabular}

Data are the mean \pm SD. $* *$ Significantly different at $p<0.005 v s$. Yakult by Student's $t$-test.

products (Figure 2), and the formation rate of the open-ring form was considered to be equivalent among the products.

Metabolism to $\mathrm{SN}-38$. When the conversion rate of irinotecan to $\mathrm{SN}-38$ by human hepatic microsomes was investigated, there were no significant differences among the products (Table V).

Cytotoxicity of $Y 3$ and $\mathrm{SN}-38$. The $\mathrm{IC}_{50}$ of $\mathrm{Y} 3$ for PC-6 and PC-9 cells was 24-fold and 64-fold higher than that of SN38 , respectively (Table VI). The Y3 content of each product was similar to or significantly lower than that of the reference formulation (Table IV). In addition, the Y3 content was approximately 45, 20,11, 8, 23 and 109 times higher than the SN-38 content in the products of Yakult, Sandoz, Nippon Kayaku, Taiho, Sawai, and Daiichi-Sankyo, respectively (Table IV). Even though Y3 was less toxic than SN-38, these differences in Y3 content might have influenced the cytotoxicity of the products. In fact, Yakult's

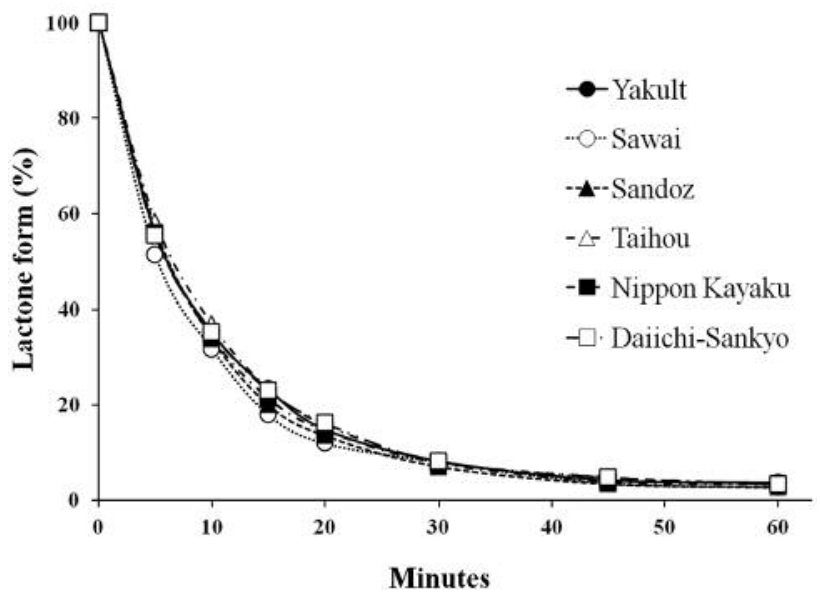

Figure 2. Elimination rate of the lactone form of irinotecan. Each irinotecan product was incubated in human blood plasma in vitro. The lactone form was changed to carboxylate form with increasing $\mathrm{pH}$ over time. There were no significant differences between products at each time point. 
Table IV. SN-38 and Y3 concentration in each product. High-performance liquid chromatography showed that the reference formulation had the highest concentration of $\mathrm{SN}-38$.

\begin{tabular}{lcccccc}
\hline & \multicolumn{5}{c}{ Product manufacturer } \\
\cline { 2 - 7 } Compound & Yakult & Sandoz & Nippon Kayaku & Taiho & \multirow{2}{*}{ Sawai } & Daiichi-Sankyo \\
\hline SN-38 $(\mathrm{ng} / \mathrm{ml})$ & $23.82 \pm 3.55$ & $14.59 \pm 2.14^{* *}$ & $22.91 \pm 4.20$ & $21.56 \pm 0.57$ & $18.16 \pm 0.86^{*}$ & $8.96 \pm 0.62^{* *}$ \\
Y3 $(\mathrm{ng} / \mathrm{mI})$ & $1069.7 \pm 64.7$ & $293.3 \pm 91.1^{* *}$ & $243.8 \pm 74.3^{* *}$ & $168.4 \pm 45.5^{* *}$ & $413.3 \pm 67.1^{* *}$ & $974.0 \pm 166.9$ \\
\hline
\end{tabular}

Data are the mean \pm SD. Significantly different at $* p<0.05$ and $* * p<0.005 v s$. Yakult by Student's $t$-test.

Table V. Formation of $S N-38$ by human hepatic microsomes. There were no appreciable differences in metabolism to $S N-38$ among the products by Student's t-test.

\begin{tabular}{lcccccc}
\hline & \multicolumn{9}{c}{ Product manufacturer } \\
\cline { 2 - 7 } & Yakult & Sandoz & Nippon Kayaku & Taiho & Sawai & Daiichi-Sankyo \\
\hline $\mathrm{ng} / \mathrm{min} / \mathrm{mgP}$ & $1.21 \pm 0.14$ & $1.15 \pm 0.07$ & $1.33 \pm 0.04$ & $1.38 \pm 0.06$ & $1.40 \pm 0.14$ & $1.40 \pm 0.07$ \\
\hline
\end{tabular}

Data are the mean \pm SD.

product, with the highest content of SN-38 and Y3, had the strongest cytotoxicity (Table III).

\section{Discussion}

In this study, we evaluated the in vitro bioequivalence of various irinotecan products and we clarified the following points. Firstly, levels of contaminants differed among the products, but were always within the acceptable range specified by the guidelines. Secondly, cytotoxicity differed significantly among the products, and these differences probably reflected differences of the SN-38 content. Finally, there were no significant differences of $\mathrm{pH}$-dependent ringopening or metabolism to $\mathrm{SN}-38$. Because irinotecan is a semisynthetic derivative of camptothecin, each product was subjected to HPLC to determine the levels of active ingredients and contaminants, and we also compared cytotoxicity, metabolism, and $\mathrm{pH}$-dependent ring opening.

Various contaminants (D1, D3, Y1, U1, etc.) were detected in addition to irinotecan and its active metabolite $\mathrm{SN}-38$. The content of each related substance differed among the products, presumably due to differences in the raw materials and manufacturing methods, but this was considered to be of no clinical relevance because the content of each substance was always within the acceptable range according to the $\mathrm{ICH}$ guidelines. Comparison of $\mathrm{pH}$-dependent irinotecan ring opening also did not significantly differ among the products. However, the MTT assay revealed significant differences of cytotoxicity among the products. Formulations of irinotecan contain trace levels of various decomposition products and contaminants,
Table VI. Cytotoxicity of $Y 3$ and $S N-38$. The $50 \%$ inhibitory concentration $\left(I C_{50}\right)$ values of $Y 3$ and $S N-38$ were measured by the 3 (4,5-dimethylthiazol-2-yl)-2,5-diphenyltetrazolium bromide assay using cancer cell lines (PC-6 and PC-9). The cytotoxicity of Y3 was much weaker than that of $\mathrm{SN}-38$.

\begin{tabular}{lcc}
\hline & \multicolumn{2}{c}{ Mean $\mathrm{IC}_{50} \pm$ S.E. $(\mathrm{nM})$} \\
Cell line
\end{tabular}

including the active metabolite $\mathrm{SN}-38$, with far stronger antitumor activity than irinotecan (100 to several thousand times higher) $(23,24)$. This study showed that the $\mathrm{SN}-38$ concentration of each product $(8.96-23.82 \mathrm{ng} / \mathrm{ml})$ was far lower than the irinotecan concentration $(20 \mathrm{mg} / \mathrm{ml})$. If irinotecan was partially metabolized to SN-38 during the MTT assay, the amount of SN38 produced would be far higher than the initial content in each product, which might suggest there was little likelihood of the differences in the baseline concentration of SN-38 causing the differences in cytotoxicity among the products. However, there was no significant difference in the metabolism of irinotecan to SN-38 by hepatic microsomes among the products and cytotoxicity in the MTT assay was related to the concentration of $\mathrm{SN}-38$ in each product, suggesting that the differences in cytotoxicity among the products were actually related to differences of the baseline SN-38 concentration. 
We also compared cytotoxicity between SN-38 and Y3, a related substance with a similar structure to $\mathrm{SN}-38$. Although the cytotoxicity of Y3 was lower than that of SN-38, the Y3 content of each product was 8-109 times higher, suggesting that Y3 was likely to influence the results of the MTT assay. In fact, Yakult's product, with the highest SN-38 and Y3 content, had the strongest cytotoxicity and the product of Daiichi-Sankyo with a Y3 content 109-fold higher than that of SN-38 $(8.96 \pm 0.62 \mathrm{ng} / \mathrm{ml}$ vs. $974.0 \pm 166.9 \mathrm{ng} / \mathrm{ml})$ exhibited relatively strong cytotoxicity against A549 and NIH:OVCAR-3 cells.

However, it must also be considered whether such in vitro differences among the products could lead to clinical differences in safety and pharmacokinetics. The concentration of irinotecan in each product was $20 \mathrm{mg} / \mathrm{ml}$, which was many times higher than that of SN-38 (8.96-23.82 ng/ml) and Y3 (168.4-1,069.7 $\mathrm{ng} / \mathrm{ml})$. Moreover, the area under the plasma concentration-time curve for plasma SN-38 was found to be approximately $0.03-0.08$ times that of irinotecan in clinical studies (25-27). The SN-38 concentrations of the products were much lower than that generated from irinotecan in plasma. Hence, the differences of SN-38 concentrations of the products would have little influence on in vivo cytotoxicity, indicating that each product is considered to be equivalent. The $\mathrm{SN}-38$ concentrations of the generic products were similar to or lower than that of reference formulation, indicating that there is little likelihood of the generic products having stronger clinical cytotoxicity.

In summary, based on the results of the present study, we concluded that each irinotecan product tested was equivalent to the reference formulation.

Irinotecan causes various adverse reactions, including myelosuppression and diarrhea $(28,29)$. We consider that bioequivalence should be investigated for injectable drugs with strong toxicities such as anticancer agents. If possible, clinical studies should be performed to assess the safety and efficacy of generic products before their approval. Although large-scale clinical studies are undoubtedly expensive, in vitro studies such as the present investigation can provide an indication of bioequivalence. In the future, it would seem necessary to conduct further studies to determine whether the differences among products that we identified influence the efficacy and adverse reactions of these products in clinical practice.

\section{References}

1 Sagara Y, Rai Y, Sagara Y, Matsuyama Y, Baba S, Tamada S, Sagara $\mathrm{Y}$ and Ando M: Comparison of the pharmacokinetics and safety of a paclitaxel injection NK and Taxol injection in breast cancer patients. Gan To Kagaku Ryoho 36: 247-250, 2009.

2 Takahara S, Yamamoto H, Tokushima Y and Shiba E: Safety evaluation of paclitaxel injection NK in adjuvant therapy for breast cancer. Gan To Kagaku Ryoho 36: 1851-1856, 2009.

3 Tsukiyama I, Hotta K, Takeuchi M, Onishi M, Toyama Y, Saito H, Sai Y, Miyamoto K and Hasegawa T: Evaluation of safety in clinical use of generic paclitaxel $[\mathrm{NK}]$ for injection. Gan To Kagaku Ryoho 39: 613-617, 2012.

4 Yamamoto D, Tsubota Y, Sueoka N, Yokoi T, Inoue K, Ohira M and Muranaka T: Comparison of a safety evaluation between paclitaxel injection NK and Taxol. Gan To Kagaku Ryoho 40: 959-961, 2013.

5 Poirier E, Desbiens C, Poirier B, Hogue JC, Lemieux J, Doyle C, Leblond AF, Cote I, Cantin G and Provencher L: Comparison of serious adverse events between the original and a generic docetaxel in breast cancer patients. Ann Pharmacother 48: 447$455,2014$.

6 Ochi N, Yamane H, Hotta K, Fujii H, Isozaki H, Honda Y, Yamagishi T, Kubo T, Tanimoto M, Kiura K and Takigawa N: Cisplatin-induced hyponatremia in malignancy: comparison between brand-name and generic formulation. Drug Design Deve Ther 8: 2401-2408, 2014.

7 Oike T, Ohno T, Noda S-e, Sato H, Tamaki T, Kiyohara H, Ando $\mathrm{K}$ and Nakano $\mathrm{T}$ : Comparison of hematological toxicities between innovator and generic cisplatin formulations in cervical cancer patients treated with concurrent chemoradiotherapy. J Radiat Res (Tokyo) 54: 474-478, 2013.

8 Sekine I, Kubota K, Tamura Y, Asahina H, Yamada K, Horinouchi $\mathrm{H}$, Nokihara $\mathrm{H}$, Yamamoto $\mathrm{N}$ and Tamura $\mathrm{T}$ : Innovator and generic cisplatin formulations: comparison of renal toxicity. Cancer Sci 102: 162-165, 2011.

9 Hsiang YH, Hertzberg R, Hecht S and Liu LF: Camptothecin induces protein-linked DNA breaks via mammalian DNA topoisomerase I. J Biol Chem 260: 14873-14878, 1985.

10 Satoh T, Hosokawa M, Atsumi R, Suzuki W, Hakusui H and Nagai E: Metabolic activation of CPT-11, 7-ethyl-10-[4-(1piperidino)-1- piperidino]carbonyloxycamptothecin, a novel antitumor agent, by carboxylesterase. Biol Pharm Bull 17: 662664, 1994.

11 Kawato Y, Aonuma M, Hirota $\mathrm{Y}$, Kuga $\mathrm{H}$ and Sato $\mathrm{K}$ : Intracellular roles of $\mathrm{SN}-38$, a metabolite of the camptothecin derivative CPT-11, in the antitumor effect of CPT-11. Cancer Res 51: 4187-4191, 1991.

12 Douillard JY, Cunningham D, Roth AD, Navarro M, James RD, Karasek P, Jandik P, Iveson T, Carmichael J, Alakl M, Gruia G, Awad L and Rougier P: Irinotecan combined with fluorouracil compared with fluorouracil alone as first-line treatment for metastatic colorectal cancer: a multicentre randomised trial. Lancet 355: 1041-1047, 2000.

13 Sanchez R, Esteban E, Palacio I, Fernandez Y, Muniz I, Vieitez JM, Fra J, Blay P, Villanueva N, Una E, Mareque B, Estrada E, Buesa JM and Lacave AJ: Activity of weekly irinotecan (CPT11) in patients with advanced non-small cell lung cancer pretreated with platinum and taxanes. Invest New Drugs 21: 459-463, 2003.

14 Kohne CH, Catane R, Klein B, Ducreux M, Thuss-Patience P, Niederle N, Gips M, Preusser P, Knuth A, Clemens M, Bugat R, Figer I, Shani A, Fages B, Di Betta D, Jacques C and Wilke HJ: Irinotecan is active in chemonaive patients with metastatic gastric cancer: a phase II multicentric trial. Br J Cancer 89: 9971001, 2003.

$15 \mathrm{Xu} \mathrm{L}, \mathrm{Wu} \mathrm{X}, \mathrm{Hu} \mathrm{C}$, Zhang Z, Zhang L, Liang S, Xu Y and Zhang F: A meta-analysis of combination therapy versus singleagent therapy in anthracycline- and taxane-pretreated metastatic breast cancer: results from nine randomized Phase III trials. OncoTargets Ther 9: 4061-4074, 2016. 
16 Sugiyama T, Yakushiji M, Noda K, Ikeda M, Kudoh R, Yajima A, Tomoda Y, Terashima Y, Takeuchi S, Hiura M, Saji F, Takahashi T, Umesaki N, Sato S, Hatae M and Ohashi Y: Phase II study of irinotecan and cisplatin as first-line chemotherapy in advanced or recurrent cervical cancer. Oncology 58: 31-37, 2000.

17 Shoji T, Takatori E, Omi H, Kumagai S, Yoshizaki A, Yokoyama Y, Mizunuma H, Fujimoto T, Takano T, Yaegashi N, Tase T, Nakahara K, Kurachi H, Nishiyama H and Sugiyama T: Phase II clinical study of the combination chemotherapy regimen of irinotecan plus oral etoposide for the treatment of recurrent ovarian cancer (Tohoku Gynecologic Cancer Unit 101 Group Study). Int J Gynecol Cancer 21: 44-50, 2011.

18 Gallo RC, Whang-Peng J and Adamson RH: Studies on the antitumor activity, mechanism of action, and cell cycle effects of camptothecin. J Natl Cancer Inst 46: 789-795, 1971.

19 Wall ME, Wani MC, Cook CE, Palmer KH, McPhail AT and Sim GA: Plant Antitumor Agents. I. The Isolation and Structure of Camptothecin, a Novel Alkaloidal Leukemia and Tumor Inhibitor from Camptotheca acuminata. J AM Chem Soc 88: 3888-3890, 1966.

20 Akimoto K, Kawai A and Kazumi O: Simultaneous determination of a camptothecin derivative, used as an anticancer drug, and its photodegradation products by high-performance liquid chromatography. J Chromatogr A 734: 401-404, 1996.

21 Sano K, Yoshikawa M, Hayasaka S, Satake K, Ikegami Y, Yoshida H, Ishikawa T, Sawada S and Tanabe S: Simple nonion-paired high-performance liquid chromatographic method for simultaneous quantitation of carboxylate and lactone forms of 14 new camptothecin derivatives. J Chromatogr B Analyt Technol Biomed Life Sci 795: 25-34, 2003.

22 International Conference on Harmonisation (ICH) Guidline Q3B (R2): impurities in new drug products, 2006.

23 Jansen WJ, Zwart B, Hulscher ST, Giaccone G, Pinedo HM and Boven E: CPT-11 in human colon-cancer cell lines and xenografts: characterization of cellular sensitivity determinants. Int J Cancer 70: 335-340, 1997.

24 van Ark-Otte J, Kedde MA, van der Vijgh WJ, Dingemans AM, Jansen WJ, Pinedo HM, Boven E and Giaccone G: Determinants of CPT-11 and SN-38 activities in human lung cancer cells. $\mathrm{Br}$ J Cancer 77: 2171-2176, 1998.
25 Crews KR, Stewart CF, Jones-Wallace D, Thompson SJ, Houghton PJ, Heideman RL, Fouladi M, Bowers DC, Chintagumpala MM and Gajjar A: Altered irinotecan pharmacokinetics in pediatric high-grade glioma patients receiving enzyme-inducing anticonvulsant therapy. Clin Cancer Res 8: 2202-2209, 2002.

26 Pitot HC, Goldberg RM, Reid JM, Sloan JA, Skaff PA, Erlichman C, Rubin J, Burch PA, Adjei AA, Alberts SA, Schaaf LJ, Elfring $G$ and Miller LL: Phase I dose-finding and pharmacokinetic trial of irinotecan hydrochloride (CPT-11) using a once-every-three-week dosing schedule for patients with advanced solid tumor malignancy. Clin Cancer Res 6: 22362244, 2000.

27 Stewart CF, Panetta JC, O'Shaughnessy MA, Throm SL, Fraga CH, Owens T, Liu T, Billups C, Rodriguez-Galindo C, Gajjar A, Furman WLand McGregor LM: UGT1A1 promoter genotype correlates with $\mathrm{SN}-38$ pharmacokinetics, but not severe toxicity in patients receiving low-dose irinotecan. J Clin Oncol 25: 25942600, 2007.

28 Rothenberg ML, Eckardt JR, Kuhn JG, Burris HA, 3rd, Nelson J, Hilsenbeck SG, Rodriguez GI, Thurman AM, Smith LS, Eckhardt SG, Weiss GR, Elfring GL, Rinaldi DA, Schaaf LJand Von Hoff DD: Phase II trial of irinotecan in patients with progressive or rapidly recurrent colorectal cancer. J Clin Oncol 14: 1128-1135, 1996.

29 Shimada Y, Yoshino M, Wakui A, Nakao I, Futatsuki K, Sakata Y, Kambe M, Taguchi T and Ogawa N: Phase II study of CPT11, a new camptothecin derivative, in metastatic colorectal cancer. CPT-11 Gastrointestinal Cancer Study Group. J Clin Oncol 11: 909-913, 1993
Received August 9, 2016

Revised September 5, 2016

Accepted September 12, 2016 